\title{
Bashed and Wounded: The Performance of Vulnerability in Policing
}

\author{
Stephanie N. Whitehead \\ Department of Criminal Justice and Political Science, Indiana University East, Richmond, IN, United States of America
}

\section{Email address:}

snwhiteh@iue.edu

\section{To cite this article:}

Stephanie N. Whitehead. Bashed and Wounded: The Performance of Vulnerability in Policing. International Journal of Law and Society. Vol. 4, No. 2, 2021, pp. 100-106. doi: 10.11648/j.ijls.20210402.17

Received: April 16, 2021; Accepted: May 6, 2021; Published: May 14, 2021

\begin{abstract}
This article centers on the sense of vulnerability and victimization felt by police officers in the United States. Of particular interest is how officers feel victimized by individuals and groups who offer critiques of police organizations. An analysis of the affective expressions of this sense of victimization through conversations with officers and trainers from a state in the Midwest, United States, illustrates a lingering antagonism between police and those deemed outsiders. This article specifically examines the interpretive strategies and cultural logic officers use to make meaning of themselves as victims of what they deem as unjustifiable criticism and critique by those outside the police institution. This work illustrates that the use of such rhetorical tropes as 'cop bashing' can be understood as a form of culture work used to silence alternative interpretations of policing in general and police work in particular. The culture work of 'bashing' is thus part of the cultural milieu of policing and feeds distrust in police organizations making it hard to offer meaningful critiques and recommendations for improving police work and policing organizations. Findings are discussed in relation to the implications for critical policing studies and the politics of knowledge at play in interpretations of policing actions.
\end{abstract}

Keywords: Police, Siege Mentality, Vulnerability, Cop Bashing, Police Performances

\section{Introduction}

I have always been fascinated with how many drivers immediately slow down to a crawl at the sight of a police car on American highways. My fascination is due in large part to my own participation in this phenomenon. Even when driving well below the posted speed limit, at the sight of a police car, lights flashing or not, my foot will inevitably move to the brake pedal. It seems that I am not alone in this act. Paying close attention to driving behaviors of highway motorists, I have noticed over the years that many people do the same thing. Even when traffic is moving at the posted pace, upon sight of a police car parked on the side of the road or approaching from behind, brake lights will start flashing.

I also noticed this phenomenon several times during ride alongs with officers. Upon an officer's approach, brake lights would flash even if the driver did not appear to be doing anything wrong. I pointed out my observations to two different officers on two separate occasions. I explained to both CJ and JC my somewhat obsessive fascination with this phenomenon - how at the mere sight of a police car I more or less unconsciously feel nervous and fearful, despite doing nothing seemingly illegal. My hope was that this observation would lead to conversations about the impact of police presence in even the most seemingly mundane encounters.

Both CJ and JC responded in exactly the same way. Each officer scoffed, subtly mocking my observation with rolled eyes, and forcefully subdued laughter. Both quickly dismissed my observations and immediately redirected the discussion from one about feeling nervous at sight of a police car to the many ways drivers fail to respond to an officer's presence. Instead of acknowledging and engaging in conversation about the impact police have on driver's behaviors, each officer proceeded to offer numerous examples about how disrespectful others were to police officers. Stories of how drivers would pull out in front of them without paying attention, how drivers would fail to move to the side of the road in emergencies neglecting to heed the flashing lights and sirens, and how cars would fly past them as they sat by the side of the road watching traffic in plain sight were never in short supply.

In both cases, I tried to redirect the conversation back to 
questions of police power and each time my observations were quickly dismissed. The first time this type of exchange occurred, I found the irony somewhat amusing. Such responses seemed to be both extraordinarily shortsighted and incredibly naïve given the power and privileges of the officers as members of the police force. As opposed to recognizing that there might be a reason behind citizens' apprehension, the officers' scoffed at my suggestion that someone might be afraid of them. Stories revealing their feelings of debasement at the hands of citizens, on the other hand, were plentiful and performed with the greatest seriousness and sincerity. My amusement quickly moved to frustration both at the refusal of each officer to appreciate my contribution to the discussion and at my own felt sense of methodological failure. I would eventually give up and let the conversation go on to another topic. Obviously, there was a striking disconnect between interpretations of events.

The disjuncture between the officer's focus on their own vulnerability and my focus on the extraordinary powers bestowed upon officers, and consequently, citizen fears and anxieties about those powers is symptomatic of the struggles for power taking place in and through the language and imagery of policing.

The sense of police marginalization is the main concern of this article. Of particular concern is the ways officer's make meaning of commentary about policing and police work and how these interpretations reinforce this overwhelming sense of victimization. I examine the interpretive strategies and cultural logics that generate this sense of marginalization specifically focusing on the following paradox: why, given police powers to detain, to interrupt the flow of everyday life, to watch, to frame encounters, human activity, and behaviors do officers persistently fail to understand their power to affect citizens.

\section{The Mythology of the Battered Crime Fighter}

Police scholars repeatedly support the concept of police officers imagining themselves as victims of unjustifiable scrutiny and critique arguing that officers often exaggerate the extent of all citizen opposition [1, 2, 3]). Hunt (1985) offers an analysis of this sense of victimization as an effect of the crime fighting mythology of policing [4]. In his pioneering study of the social organization of police work, Peter Manning (1997) argues that the police adopted and continually recreate the crime fighter image as a way of staking claim to a domain of professional expertise that they and they alone can control [5]. Because it does not present an accurate picture of the mundane activities in which officers primarily engage, the crime-fighting image creates a number of serious problems. For one, it means that officers ignore a wide variety of ordinary activities that consume most police time and effort, such as engaging and talking to members of a community, driving through neighborhoods, and talking to one another. Furthermore, it creates unrealistic expectations for both officers and the community. For officers, it creates the expectation that police work is all about the excitement of arresting suspects, the dangers they face, and the sense of being the thin blue line between an ordered society and chaos. For the community, it creates the expectations that officers can always solve crimes. In so doing, the crime fighter mythos creates a contradiction between what the police value and many of the mundane behaviors in which they engage. Police officers follow the rationale of their existence. Whether perceived or imagined, any sense of criticism geared toward the crime fighting mythos is thus perceived an instant threat - what Hunt (1985) calls a symbolic assault to the sanctity of the profession [4]. Kappeler et al. (1998) further note that due to the widespread and deeply embedded belief in the nobility of their profession, officers often view any seemingly lack of respect for police work as an enemy of civilized society [6]. Coupled with the propensity to focus on the possible dangers they may face, officers fail to find some analyses of police work and practice as legitimate [7].

Many officers do indeed see themselves as vulnerable and under attack and in some ways they are especially vulnerable to criticism. In the failure to contextualize the organizational and legal constraints upon officers' behaviors, the mass media do tend to sensationalize instances of police misconduct. Given officers' sense of confidence in their ability to fight crime, having a defense attorney pointing out failures in their investigations or reports does in some ways make officers look bad.

To understand why many police officers ignore the realities that shape their work environment, it is not enough to point out how misguided such positions might be. As Waddington (1999) reminds us, it is important to develop an appreciation for how officers create meaning through the interpretive strategies displayed in talk and storytelling [8].

\section{Police Victimization as Culture Work}

While much is written about overt coercive practices of policing - arrests, shootings, and obvious forms of misconduct generally - less is written about the symbolic practices - those small, seemingly inconsequential moments where boundaries are maintained and made visible $(9,10)$. The insights generated from Manning's (1997) dramaturgically informed work gave rise to a body of research addressing a still much overlooked aspect of policing: the signifying force and symbolic capacity of policing and police work [5].

Building on Pierre Bourdieu's (1991) notion of symbolic power, Loader (1997) argues that policing represents a central site for producing notions of citizenship and community, difference and belonging [9, 11]. Policing routinely communicates a range of authoritative meanings regarding order/disorder, justice/injustice, normality/deviance, inclusion/exclusion, us/them. In so doing, it operates in ways that condition individual subjectivities [12] - "helping to shape the manner in which people think, feel, and act in relation to problems of crime and disorder, their causes, and 
their effects" [13].

Policing, in this view, is thus a cultural institution and performance, a "condensing symbol through which people evoke and interpret the past, form judgments on the present, and channel fears and longings for the future" [14]. Police work is also culture work - an authoritative means of distributing risk and blame and reinforcing the boundaries and identity of cultural and political community [13]. In short, policing provides a set of meaning through which the world is interpreted. Policing thus works not just by the imposition and enforcement of rules but also by the capacity to construct authoritative images of social relationships and actions. Police discourse and practice are cultural constructs that carry powerful meanings not just to those trained as officers, but to the ordinary person as well. As Loader (2006: 211) makes clear: Every stop, every search, every arrest, every group of youths moved on, every abuse of due process, every failure to respond to call or complaint, every depiction of criminality and victimization - all these send small, routine, authoritative signals about society's conflicts, cleavages, and hierarchies, about whose claims are legitimate within it and about whose status identity is to be affirmed or denied as part of it [13]. This suggests that even the most ordinary aspects of police behavior are significant to the struggles taking place between officers and those outside the policing sphere.

In creating specific meanings, policing signals which concerns about policing and police power are legitimate and which are considered irrelevant. The examination of the interpretive strategies in this study adds to this literature by looking in detail at the nuanced ways officers make meaning of this sense of victimization and how specific expressions of vulnerability work to silence those voices expressing concerns with policing and specific police practices.

\section{Vocabularies of Police Victimization}

Clearly, the officers did not share my understanding. For them, even the slightest deviation from utter devotion to policing is likely to be dubbed cop bashing or at the very least anti-police. Instead of respecting those voices concerned with police power by addressing topics and situations that would speak to those concerns, officers and trainers alike readily dismissed any observation that might be read as harboring inklings of negative judgment. The linkages between questioning police activities and anti-police sentiment was a constant tension in conversation and training.

Cop Bashing

Equating critique and concern with police misconduct, inequality, or any issue of police reform as cop bashing and an overall anti-police sensibility was an especially troubling discursive current running throughout my conversations with officers and in the trainings. Cop bashing is an idiom pivotal in disputes over police reform. Cop bashing is often invoked a common objection to research findings and discussions about police misconduct generally [15]. In mass mediated controversies, for instance, charges of cop bashing are repeatedly made by some journalists and police experts against those who spoke out about against the behavior of the officer involved in the situation [16].

That the officers refused to seriously consider the effect of their presence on those whom they encounter may seem like random blindness and insensitivity at the individual level. However, this short sightedness is culturally constructed. Indeed, it stems precisely from the crime fighting mythos.

Although I am somewhat liberal in the traditional, stereotypical usage of the term (i.e. concerned with civil rights in the legal system, concerned with gender, racial, and social class equality, etc.); I do not equate being liberal with being anti-police. Given the history of policing and its relation to class and racial oppression [17], I also do not consider it naïve or anti-police to question why and how the police do what they do. Nor do I consider questioning any police activities, practices, and beliefs to be about cop bashing.

As opposed to taking mass media accounts of misconduct, the defense attorney's role in protecting civil liberties, or academic inquiry into police work as serious and worthwhile, and engaging in training practices that might address ethical problems as serious matters, policing critiques were instead portrayed as the cries of the pathological. As opposed to recognizing misconduct as a serious concern, and taking responsibility by addressing the potential for misconduct in all aspects of police work and training, there was a tedious pattern of deflection. For the first few days of each training course, very few of the officers would initiate conversations. Any talk was primarily small talk; it was as if officers were tiptoeing around me. The trainers would warn me prior to the beginning of each course to expect officers to be suspicious of my presence. To ease the tension, the trainer introducing me to the class would often joke about my being from internal affairs, and FBI informant, or a spy. In my introduction, I would explain to the class that I was observing them as part of my dissertation research, my academic interests in policing, and my academic affiliation with a University. I would always jokingly assure them that I was not, in fact, from internal affairs. During breaks I would often join some of the officers outside the building for a cigarette. Being a smoker provided a great opportunity to informally talk with officers and ask questions. On one occasion, I was talking with a group of officers about media accounts of police shootings continuing the discussion from the session related to talking with the media. The class was instructed to never talk to the media, to either let superiors or a designated media relations officer talk to them, because one "never knows how they will twist whatever you say or do". This led to a discussion about the inaccuracy of media accounts of police activity.

Outside, the officers condemned the mass media for intentionally making cops "look bad", "like a bunch of racist assholes" and for the "liberal bias of the media". During the course of the conversation, I made a seemingly simple comment acknowledging my agreement that mass media accounts do not always adequately account for the 
complexity involved in a variety of situations. It is important to note here, for reasons that I hope will become clear, that I never made mention that media coverage was necessarily wrong or unimportant; just that coverage tends to simplify matters. One of the officers, an older white man, his eyes growing big, looked shocked and surprised by my comment. He started to laugh: "I wish they had more like you on this campus. This campus is full of liberal cop bashers". The other four officers standing with us began to join in with the officer's laughter and there were several nods of agreement with his assessment.

Despite their protestations that the mass media make them look racist or just generally bad, police officers are, for the most part, presented in a positive light in the mass media and other cultural representations. In his analysis of police procedurals, for instance, Lane (2001) notes that even though the police officer has been shown to fail occasionally be it through a temporary lapse in judgment or other "bad" act, he/she is still routinely depicted as the public hero [18]. Also, like male bashing, the literal dangerousness posed to officers by citizens is largely overemphasized and exaggerated. FBI and DOJ reports, for instance, reveal that many more individuals die at the hands of the police than officers are feloniously killed in the line of duty (see tables 1 and 2).

Table 1. DEATHS IN POLICE CUSTODY (United States, 2003-2006).

\begin{tabular}{lllll}
\hline $\mathbf{2 0 0 3 - 2 0 0 6}$ & & $\mathbf{2 0 0 3}$ & $\mathbf{2 0 0 4}$ & $\mathbf{2 0 0 5}$ \\
\hline All causes & 2,686 & 627 & 670 & 679 \\
Homicide & 1,540 & & & \\
By law enforcement & 13 & 366 & 367 & 368 \\
By other persons & 317 & 3 & 4 & 4 \\
Drug/alcohol intoxication & 289 & 83 & 79 & 85 \\
Suicide & 182 & 59 & 84 & 79 \\
Accidental injury & 139 & 52 & 41 & 47 \\
Illness/natural causes & 206 & 27 & 46 & 32 \\
Other/unknown & 37 & 49 & 64 \\
\hline
\end{tabular}

Bureau of Justice Statistics, Deaths in Custody, 2003-2006.

Table 2. LAW ENFORCEMENT KILLED IN THE LINE OF DUTY (United States, 2003-2006).

\begin{tabular}{|c|c|c|c|c|c|}
\hline & 2003-2006 & 2003 & 2004 & 2005 & 2006 \\
\hline Officer's feloniously killed & 212 & 52 & 57 & 55 & 48 \\
\hline Killed by accident & 296 & 81 & 82 & 67 & 66 \\
\hline
\end{tabular}

Federal Bureau of Investigations, Law Enforcement Officers Killed \& Assaulted, 2003-2006

A deep sensitivity to any glimmer of judgment made about their work was prominent in many of my conversations with officers. Whether it was the "liberal media" out to twist "everything into an act of bad policing", defense attorneys out to "discount every word you say", or "citizens' blaming the police" for all sorts of behaviors, trainers and officers alike repetitively conjured notions of officers as victimized and traumatized by a variety of outside sources. I was quite frequently surprised that officers' were so deeply sensitive to, not even critique, but to any opinion made about their work.

Throughout these discussions with individual officers, they seemed equally surprised that I was not more critical of the police. When talking with officers about the fact that I had family who were police officers or if I gave any small indication that I might somehow sympathetic to their work and experience, there was an almost perceptible sigh of relief. There was a lull in the tension once they presumed that I was not there to attack them or make them look bad.

As a scholar concerned with civil rights, I find this conflation rather troubling and uncannily similar to the "male bashing" trope that is often used by some as an expression to describe the criticisms of masculinity waged by feminists. In her examination of the discourse of male bashing, feminist philosopher Sue Cataldi (1995: 76-77) notes that: To "bash" means to violently strike with a heavy, crushing blow. Colloquially, it connotes an indiscriminate (a random, confused) lashing out and also suggests that the striking of this blow is unfair, undeserved, or prejudiced. Sometimes the bashing is physical as in "gay bashing" when persons are violently attacked or mercilessly beaten because of their membership in a group. Sometimes the word "bashing" indicates verbal abuse a form of unjust criticism or condemnation, on the order of scapegoating when one (convenient) group is made to bear the blame for the crimes, or the misfortunes, of others.

By conjuring up images of abused men "bashed" by women and casting women in the role of bashers, it reverses what actually happens. This table turning can then operate, perniciously, as a form of victim blaming and as a means of exaggerating the severity of any harm done to men who are, supposedly verbally, "bashed." Another shady reason for using this expression and co- opting its image of brutality is, I suspect, to lead us into thinking that the "male bashing" women supposedly do is relevantly similar or equivalent to or perhaps (since "bash" seems to me to be a stronger word than "batter") even worse than what men do to women. Those who use the expression may also be attempting to siphon attention and support away from women who are physically harmed by men and, in a subtle slip from the first to the second sense of "bashing," to marshal the maximum amount of sympathy possible for "bashed" men who are really "innocent victims" and the target of unfair criticism. 
The rhetorical trope of cop bashing seems to work in much the same way. Instead of recognizing the power that officers have by virtue of their positions, they reposition themselves as the victims of others who are treating them much worse than they treat anyone else. Like with male bashing, however, cop bashing both literally and metaphorically is hardly representative of the reality.

\section{Evaluating Critique}

Police training is an arena that mediates cultural fantasies and anxieties about police work. The proclivity toward overemphasizing the crime fighting aspects of policing, the dangerousness of the job, and other infrequent critical incidents (e.g. firearms skills, self-defense, interrogation) reinforces the most stereotypical characterizations of police work [19]. The state of exaggerated fear, cynicism, and mistrust of those outside policing which often leads to resentment toward outsiders on the part of officers is thus perpetuated in the police training environment.

I learned very quickly There was only one difference that mattered: the difference between us, occupants of the police profession, and them, those outside the policing sphere.

While I expected officers to be wary, and even resentful of others, I was surprised by the way both trainers and officers interpreted others intentions and motivations. An inordinate amount of attention and misinformation concerning the motivations of others' interest and assessments of the police was disseminated to officers during police trainings and was a source of conversation for officers during breaks. The tendency to equate concern with civil rights, police misconduct, or inequality in policing as radically anti- police is a common error reproduced and perpetuated in police training - it was an error I encountered quite often.

Little time in training was spent on developing an understanding of constitutional law, civil rights, or ethical considerations in the enforcement of law. This is not to say, nor should it be interpreted, however, that the police are wholly unconcerned with stopping police misconduct or largely indifferent to individual's civil rights. It is just that the crime fighting orientation prioritizes concerns elsewhere. Training priorities are oriented toward better tactical applications that might aid in an arrest, confession, or other crime fighting activity, not the ethical dilemmas involved in those activities. Similar hyperbolic characterizations of others motivations occurred throughout the training in various forms from several of the trainers:

Trainer 1: The media will do what they have to do; it's their job to make you look bad.

Trainer 2: That is what the defense does. They get criminals off - that is their job.

Trainer 5: C'mon they are lawyers it's their job to make you look bad.

Taking the quotes by three of the trainers above literally, one would assume that the only reason one becomes a lawyer is to either flood the streets with criminals or the make officers look terrible. Lawyers, specifically defense attorneys, the mass media, and liberals were especially denigrated as only "out to get" the police in one form or another.

The first presenter in all the courses was a lawyer who addressed the particular legal issues pertinent to each aspect of that individual course. In each course, she carefully detailed what behaviors were and were not in violation of constitutional provisions. In the Criminal Investigations course, for instance, she laid out in detail the contours of "good and bad policing practices" in the context of Fourth Amendment jurisprudence as evinced in her following words of caution: "you cannot, I repeat, cannot, search anywhere outside the confines of the warrant. Got it?" Even so, the crime control focus prioritizes police officer's concerns toward the technical aspects of policing. As one instructor noted in relation to the lawyer's warning above:

Trainer 1: when writing out the warrant, be sure like if you are looking for a gun for example, to include bullets or other small objects in the warrant. That way you aren't confined in where you can search, you can search smaller places. You never know what you might find.

A different instructor, also speaking to the warnings addressed by the lawyer the previous day, warned officers that:

Trainer 3: Once you locate the items listed (on the warrant), just like (the lawyer) told you on Monday the search must stop. So, be creative, take time to assess the situation and your environment. If there are people around try to get them talking...remember, there may be something hiding right in front of you, so take your time.

There was no indication of concern for the potential abuse - the violation of individual's rights - that might occur out such advice. There was no debate about the ethical quandary entailed in 'taking your time' or 'being creative'. Instead, officer's priorities are aimed toward using what they can to detect crime and criminals. The advice offered was all about teaching and learning better tricks and tools of the trade. That ethical dilemmas were not presented as a cause of concern in the training context may not be an intentional omission, but it is certainly a socially structured failure of imagination. I am quite aware that my liberal sensibilities do frame my seeing potential abuses contained within the advice above. However, uneasiness with police power is not something to be easily brushed aside, silenced through the derogatory characterizations of cop bashing.

The criticisms posed by individuals concerned with police power are hardly unjust or unfair. Questioning the police and their practices is not about attacking the police. It is not about making officers look bad. It is about addressing real ethical, cultural, and social issues that occur in the routine performance of police work. Characterizing the expression of such concerns as attacks or bashing is clearly an over exaggeration of the harm such expressions create. 


\section{Conclusion}

The police do indeed see themselves as under attack and, as Bratton's speech makes clear, are often unwilling to see critiques as anything more than unjustified criticism [20]. While the crime fighting identity and priorities are undeniably important to understanding the experience and affective understandings of police officers, the sense of marginalization and vulnerability expressed by the officers and trainers is equally important to consider.

In some ways they are susceptible to criticism. In the failure to contextualize the organizational and legal constraints upon officers' behaviors, the mass media do tend to sensationalize instances of police misconduct [21]. Given officers' sense of confidence in their ability to fight crime having a defense attorney pointing out failures in their investigations or reports, or having a researcher point out the limitations of your ability to do what you believe your job entails it is easy to understand why officers feel they are made to look "ineffective" or generally "bad". That officers feel vulnerable to attack or victimized, however, does not make the effects of their normative positions disappear, nor does it absolve policing of responsibility for their role in the harms perpetuated by their failure to consider the experience of those outside the policing experience.

By re-imagining and positioning themselves as more vulnerable than the populations they police. officers fail to account for others' expressions of vulnerability - anger, anxieties, and a general concern in regards to cases of police misconduct, for instance - seeing them instead as irrational displays and personal attacks. One complaint routinely made by many in the African-American community is the failure of the police to understand and take seriously citizens fears and anxieties of police misconduct [22]. In failing to give respect to the voice and experiences of those concerned with police power, officer's interpretation of concerns intensifies the boundaries between the police and some citizens.

The expressions of police as victims of unjustifiable criticism, however, is not isolated to the police themselves - a possible testament to the ability of the police to control the meanings of alternative interpretations. Indeed there has been an increasingly troubling need to explicitly state in research publications that one's work is not an exercise in 'cop bashing' for some researchers to go so far as to characterize certain strains of research as amounting to nothing more than 'police bashing' [8]. Journalists and politicians too are quick to discredit critical analyses of specific mass mediated cases of police misconduct as displays of cop bashing [16]. This discursive current further legitimizes these sense of police vulnerability by engaging in the same discrediting tactics. This is troubling as this discursive current works to discount many analyses designed not with the intention of cop bashing, but is instead designed to make policing aware of its role in the protection and security of all citizens by exposing ways departments silence less authoritative voices.

In understanding how officers imagine themselves as based and wounded, this study hopes to make explicit just how sensitive officers are to even seemingly innocuous critiques. In so doing it may contribute to a more productive dialogue between police practitioners and those whose analyses they imagine as irrelevant to the understanding and practice of policing. This study included illustrations of the interpretive strategies used to make meaning of perceived criticisms of police work. Further analysis of how officers make meanings of outsider's motivations and how these meanings are recreated in other institutions would add a more detailed account of just how widely these meanings circulate in mass media forms and in scholarly research.

\section{References}

[1] Wilson, J. Q. (1968). Varieties of police behavior: The management of law and order in eight communities. Cambridge, MA: Harvard University Press.

[2] Westley, W. A. (1970). Violence and the police: A sociological study of law, custom, and morality. Cambridge, Mass: MIT Press.

[3] Skolnick, J. H. (1969, 1994). Justice without trial: Law enforcement in democratic society (3rd ed.). New York: Macmillan.

[4] Hunt, J. (1985). Police accounts of normal force. Urban Life, 13 (4), 315-341.

[5] Manning, P. K. (1997). Police work : The social organization of policing (2nd ed.). Prospect Heights, Ill.: Waveland Press.

[6] Kappeler, V. E., Sluder, R. D., \& Alpert, G. P. (1998). Forces of deviance: Understanding the dark side of policing (2nd ed.). Prospect Heights, Ill.: Waveland Press.

[7] Crank, J. P. (1998). Understanding police culture. Cincinnati, $\mathrm{OH}$ : Anderson.

[8] Waddington, P. A. J. (1999). Police (canteen) sub-culture: An appreciation. British Journal of Criminology, 39 (2): 287-309.

[9] Loader, I. (1997). Policing and the social: Questions of symbolic power. British Journal of Sociology, 48 (1): 1-18.

[10] Manning, P. (1998). Symbolic communication: Signifying calls and the police response. Cambridge, Mass.: MIT Press.

[11] Ericson, R. V. (1982). Reproducing order: A study of police patrol work. Toronto, CN: University of Toronto Press.

[12] Reiner, R. (1992). The politics of the police (2nd ed.). Toronto: University of Toronto Press.

[13] Loader, I. (2006). Policing, recognition, and belonging. The Annals of the American Academy of Political and Social Science, 605: 201-223.

[14] Loader, I., \& Mulcahy, A. (2003). Policing and the condition of England: Memory, politics and culture. Oxford: Oxford University Press.

[15] MacDonald, H. (2003). Are cops racist?: How the war against the police harms black Americans. Chicago, IL: Ivan Dee Publisher.

[16] Malkin, M. (2009, December 4). The war on cops. Retrieved from http://michellemalkin.com/2009/12/04/the-war-on-cops/. 
[17] Harring, S. L. (1983). Policing a class society: The experience of American cities, 1865-1915. New Brunswick, N. J.: Rutgers University Press.

[18] Lane, P. J. (2001). The existential condition of television crime drama. Journal of Popular Culture, 34 (4), 137-152.

[19] Fyfe, J. (1996). Training to reduce police-civilian violence. In W. Geller \& H. Toch (Eds.), Police violence: Understanding and controlling police abuse of force (165-179). Yale University Press.
[20] Bratton, W. J. (2006). Keynote Speech as Delivered at the 2006 National Institute of Justice Conference. Research: A practitioner's perspective, from the streets. Western Criminology Review, 7 (3): 1-6.

[21] Wender, J. (2008). Policing and the poetics of everyday life. Chicago, IL: University of Illinois Press.

[22] Birzer, M. L. (2008). What makes a good police officer? Phenomenological reflections from the African-American community. Police Practice \& Research, 9 (3), 199-212. 